\title{
The Academic Achievement of African American Students During Early Adolescence: An Examination of Multiple Risk, Promotive, and Protective Factors
}

\author{
Leslie Morrison Gutman, ${ }^{1}$ Arnold J. Sameroff, and Jacquelynne S. Eccles \\ University of Michigan
}

This study examined the effects of multiple risk, promotive, and protective factors on three achievement-related measures (i.e., grade point average, number of absences, and math achievement test scores) for African American 7 th-grade students $(n=837)$. There were 3 main findings. First, adolescents had lower grade point averages, more absences, and lower achievement test scores as their exposure to risk factors increased. Second, different promotive and protective factors emerged as significant contributors depending on the nature of the achievement-related outcome that was being assessed. Third, protective factors were identified whose effects were magnified in the presence of multiple risks. Results were discussed in light of the developmental tasks facing adolescents and the contexts in which youth exposed to multiple risks and their families live.

KEY WORDS: African American; early adolescence; academic achievement; resilience; risk factors; protective factors.

Until recently, the period of early adolescence, spanning ages 10-14, was neglected in scientific inquiry, in policy formation, and in public understanding (Carnegie Council on Adolescent Development, 1995). In recent years, however, researchers and practitioners have begun to recognize both the tremendous risks and opportunities inherent in early adolescence. Early

\footnotetext{
${ }^{1}$ To whom correspondence should be addressed at Center for Human Growth and Development, University of Michigan, 300 North Ingalls Building, 10th floor, Ann Arbor, Michigan 48109-0406; e-mail: lmgutman@umich.edu.
} 
adolescence encompasses not only rapid physiological and psychological changes associated with puberty, but also social transformations that follow the transition to middle level schools. Although these changes create vulnerability, they also provide a unique opportunity for preventive intervention. Because early adolescence is a period during which many young people are just beginning to engage in risky behaviors and make decisions that can shape their life course, it is also an excellent time to prevent damaging life patterns before they occur and promote a successful developmental trajectory (Carnegie Council on Adolescent Development, 1995).

This new emphasis on early adolescence asserts that we need to take a broader perspective when examining the factors that may be targeted in prevention. Recent research strongly suggests that risk factors tend to cluster in the same individual. Conversely, indices of successful adaptation also tend to cluster (Carnegie Council on Adolescent Development, 1995). In the past, however, the magnitude of examining multiple settings and multiple systems (Brofenbrenner, 1979) has daunted researchers trained primarily to focus on individual behavioral processes (Baldwin et al., 1993). In this study, we investigated the effects of multiple risks and positive family interaction and social support factors on the achievement-related outcomes of African American youth during early adolescence.

\section{MULTIPLE RISKS FACING AFRICAN AMERICAN YOUTH}

Although almost half of American adolescents face tremendous risks, African American adolescents are particularly vulnerable (Carnegie Council on Adolescent Development, 1995). For many African American students, academic problems either begin or accelerate in early adolescence. For instance, Gutman and Midgley (2000) found that African American early adolescents living in poverty experienced a significant decline in grade point average from fifth to sixth grade. In another study of poor minority youth, Seidman, Allen, Aber, Mitchell, and Fienman (1994) found that self-esteem, class preparation, and grade point average also declined significantly after the middle school transition (Seidman et al., 1994). Moreover, although African American students begin school with test scores that are similar to their European American peers, by middle school, many African American students have fallen two-grade levels behind (Steele, 1992). Students who do not successfully negotiate this transition may be at risk for long-term, negative outcomes such as school failure or school dropout or both (Finn, 1989).

Certain demographic factors such as socioeconomic status (SES) place African American children at risk for less than optimal development, yet few studies have looked beyond single variables to examine how multiple factors 
influence African American children and adolescents (Ford, 1993). Many investigators who started out examining a single risk factor soon realized that risk rarely occurs alone, rather risk tends to cluster in the same individual (Masten \& Coatsworth,1998). Because children often experience many risks, examining a single risk factor does not address the reality of most children's lives.

The examination of multiple risk factors is increasingly being seen in research. For example, Rutter (1979) found that it was not any particular risk factor but the number of risk factors in a child's background that led to a psychiatric disorder. In his sample of 10-year olds, psychiatric risk rose from $2 \%$ in families with zero or one risk factors to $20 \%$ in families with four or more risk factors. Similar findings were evident in research conducted by Sameroff and colleagues (Sameroff, Seifer, Baldwin, \& Baldwin, 1993; Sameroff, Seifer, Barocas, Zax, \& Greenspan, 1987). They found that the more risk factors that children experienced the worse their developmental outcomes.

Generally, risk factors have been defined as variables that "have proven or presumed effects that can directly increase the likelihood of a maladaptive outcome" (Rolf \& Johnson, 1990, p. 387). Risk factors that have been linked to poor developmental outcomes are consistent across several studies. Maternal mental health characteristics such as depression have been related to a number of socioemotional and cognitive problems in both children and adolescents (Rutter, 1979; Sameroff et al., 1987, 1993; Werner, 1985). Measures of SES including maternal education, income, and occupational status have also been shown to have significant effects on numerous outcomes including achievement test scores, course failures, and completed years of schooling (McLoyd, 1990, 1998). Research also suggests that children who grow up in single parent homes are less successful, on average, than children who grow up in two-parent homes. These differences have been found to relate to a broad range of outcomes and often persist into adulthood (Furstenberg, Brooks-Gunn, \& Morgan, 1987; Haveman \& Wolfe, 1991; McLananhan \& Sandefur, 1994; Werner, 1985). A larger family size, or a greater number of children living in the home, has also been shown to negatively impact children and adolescents (Rutter, 1979; Sameroff et al., 1987, 1993; Werner, 1985). Family life stresses also exact a toll on children and adolescents (McLoyd, 1998). For example, Shaw and Emery (1988) found that children exposed to a greater number of family life stresses had more internalizing symptoms, more behavior problems, and lower feelings of selfworth than children exposed to fewer family life stresses. Research has also demonstrated that neighborhood characteristics influence the academic outcomes of children and adolescents (Brooks-Gunn, Duncan, Klebanow, \& Sealand, 1993; Duncan, 1994). For example, adolescents who grow up in 
neighborhoods with a higher percentage of affluent families complete more years of schooling and have lower school dropout rates than adolescents from similar families who grow up in poorer neighborhoods (Brooks-Gunn et al., 1993; Duncan, 1994).

\section{POSITIVE FACTORS FOR AFRICAN AMERICAN YOUTH}

Despite the odds, a number of children and adolescents living in very risky contexts are able to overcome these difficulties and experience successful lives. However, investigators have only recently begun to explore the lives of these so-called "resilient" children for whom positive outcomes have been reported (Garmezy, 1993). For children who succeed despite less than optimal conditions, the presence of protective factors may compensate for the risks that exist in their lives and environments (Garmezy, 1993). Protective factors, as defined by Garmezy (1983), are "those attributes of persons, environments, situations, and events that appear to temper predictions of psychopathology based upon an individual's at-risk status" (p. 73).

The differentiation between risk and protective factors, however, is far from clear (Sameroff \& Seifer, 1987), and there continues to be many theoretical and methodological limitations in both their identification (Luthar \& Zigler, 1991) and application (Leffert et al., 1998). Although Rutter (1987) has argued that protective factors can only have meaning in the face of adversity, in most studies, protective factors have been defined as simply the positive pole of risk factors (Stouthhamer-Loeber et al., 1993). In this sense, Sameroff (1999) proposed that a better term for the positive end of the risk dimension would be promotive rather than protective factors.

In this study, we tested for both promotive and protective effects. According to Sameroff (1999), a promotive effect would be found in both high and low risk populations. Therefore, we examined evidence for a promotive factor in the linear component or direct effect of the positive variable. On the other hand, an interactive, protective effect would either have no effect in low risk populations or be magnified in the presence of one or more risk variables (Rutter, 1987). Therefore, we examined evidence for a protective effect in the nonlinear or interactive component between the positive variable and multiple risk score.

The positive variables were based on Garmezy's review of research on stress-resistant children (Garmezy, 1993). Garmezy (1993) identified variables that have been found to have positive effects on children and adolescents including (1) characteristics of the family context such as supportive, involved parenting; and (2) the availability of external support systems, as exemplified by a concerned teacher. Within this framework, we included 
(1) family factors including consistent discipline, decision making in the family, and parental school involvement; and (2) social support factors including teacher support and peer support.

\section{Family Factors}

Parents can influence their children directly through family interaction patterns and indirectly through interactions with other settings in which their children are involved such as schools. In terms of more direct parenting practices, consistent discipline has been associated with positive achievementrelated outcomes for children and adolescents (Clark, 1983; Grolnick \& Ryan, 1989; Walker, Stieber, Ramsey, \& O' Neill, 1991). For example, in a study of poor African American families, Clark (1983) found that parents of high-achieving adolescents exercised more consistent rule enforcement than did parents of low-achieving adolescents.

In addition to establishing clear, consistent discipline, effective parents also modulate their parenting in response to the developmental needs of their child (Clark, 1983). Because one of the central tasks of adolescence is to develop as an autonomous being, opportunities for decision making in the family become particularly important in early adolescence (Eccles et al., 1993). In fact, research has shown that family environments that encourage the adolescents' role in decision making are associated with more positive school adjustment, higher self-esteem, and greater satisfaction with school and student/teacher relations (Epstein \& McPartland, 1977; Lord, Eccles, \& McCarthy, 1994). For example, in a study of low- and middle-income European American youth in early adolescence, Lord et al. (1994) found that students who perceived more democratic decision-making in their families also reported more positive school adjustment and experienced increases in self-esteem after the transition to junior high school.

Parents also influence their children indirectly through involvement in their school. Parental involvement is a critical factor in children's school achievement at all grade levels. Parental involvement also varies widely by ethnicity and income level and thus may help explain differential achievement levels (Clark, 1983; Comer, 1980; Eccles \& Harold, 1993; Epstein, 1987, 1990; Gutman \& McLoyd, 2000; Tienda \& Kao, 1994). For example, parental school involvement has been positively associated with school achievement in studies of poor urban youth (Clark, 1983; Gutman \& McLoyd, 2000; Tienda \& Kao, 1994). Despite evidence documenting their positive effects, however, there is little information concerning the promotive and protective roles of consistent discipline, democratic decision-making, and parental school involvement in the academic achievement of African American youth during early adolescence. 


\section{Social Support Factors}

Social support, which has been defined as information leading the individual to believe that he or she is cared for, loved, esteemed, and valued, is considered an important positive factor for children, adolescents, and adults. Although findings are sometimes inconsistent, studies have demonstrated the beneficial effects of social support on children and adolescents' achievement (Cauce, Hannan, \& Sargeant, 1992; Dubow \& Tisak, 1989; Dubow, Tisak, Causey, Hryshko, \& Reid, 1991; Gutman \& Midgley, 2000). Studies focusing on the achievement of poor and minority children, in particular, have emphasized the importance of having supportive relationships with teachers, peers, and other adults (e.g., Clark, 1983; Comer, 1980; Rutter, 1979).

Researchers have also found that support from difference sources (e.g., peers, teachers, other adults) may be differentially related to achievementrelated outcomes. According to Hartup (1978), peers and adults may provide different support functions, thus influencing different outcome variables. For instance, in a sample of third through fifth graders, Dubow et al. (1991) found that although change in peer support was positively related to both changes in teachers' reports of student competencies and grade point average, no effects were found for teacher support or change in teacher support over time (Dubow et al., 1991). Yet, a study of early adolescence found that school support was positively related to school competence, whereas peer support was negatively related to school competence (Cauce et al., 1992). These studies suggest that we need to consider the contributions of different sources of support in predicting academic achievement particularly in early adolescence when individuals are especially concerned with peers relationships and are in need of close adult friendships outside the home (Eccles \& Midgley, 1989). Few studies have examined the promotive and protective effects of both teacher and peer support on the achievement of African American youth during early adolescence.

\section{RESEARCH QUESTIONS}

In this study, we examined the effects of multiple risk and positive factors on achievement-related outcomes for African American youth during early adolescence. For strategic purposes, we defined negative demographic and structural variables as risk factors and parent interaction and social support variables as positive factors to emphasize the interplay between these two sets of influences on adolescent development. As efforts to understand resilience require multifaceted appraisals of risk factors in children's lives 
(Masten \& Coatworth, 1998), we calculated a multiple risk score for each family on the basis of factors shown to have deleterious effects on children and adolescents. These factors included maternal depression, family income, highest occupation in the household, maternal education, marital status, number of children living in the household, family stressful events, percent neighborhood poverty, percent neighborhood female headed households, and percent neighborhood welfare recipients.

In addition to measuring multiple risk factors, we also examined the differential effects of diverse types of positive variables that impinge on adolescents. Most studies of high risk African American youth, in particular, have focused primarily on the role of the family. Less attention has been placed on other important sources of support, such as school personnel and peers, which Eccles and Midgley (1989) suggest, are especially critical during early adolescence. In this study, we examined family behavioral factors including consistent parenting, democratic decision-making, and parental school involvement as well as social support factors including teacher and peer support.

We also tested the positive variables to determine whether they had promotive (i.e., direct) and/or protective (i.e., interactive) effects. For the most part, previous studies have focused on how positive factors influence the developmental outcomes of either low risk or high risk adolescents. In many studies of resilience, there has also been a confound between high risk samples and ethnic differences (e.g., the high risk groups are primarily African American, whereas the low risk groups are primarily European American; Baldwin et al., 1993). Because our sample included African American families with a wide distribution of exposure to risk, we were able to test for both promotive and protective effects.

Rather than examining only a single academic outcome, we also examined three different, separate measures of achievement for several reasons. First, grade point average, number of absences, and achievement test scores reflect the diverse types of behaviors that are involved in school achievement. Number of absences may reflect more of the behavioral aspects of schooling, whereas grade point average and achievement test scores may be more closely tied to learning and ability. Second, different predictors may emerge as significant depending on the particular achievement-related outcome being assessed. For example, SES has been found in some studies of African American adolescents to have no relation to achievement when high school grades are the achievement indicator, but to have small but significant relations to achievement when achievement tests are used (Slaughter \& Epps, 1987). Third, different biases may be inherent in these measures particularly for African American youth. For example, according to Steele (1992) even when African American students are better prepared in terms of 
their scores on achievement tests, they are more likely to achieve less in subsequent schooling than are European American students (i.e, have poorer grades and lower graduation rates). Considering these factors, it seems particularly important to have a multifaceted view of achievement particularly when examining African American adolescents exposed to multiple risks.

We tested three main hypotheses: (a) African American youth who were exposed to more risk factors will have lower grade point averages, more absences, and lower math achievement test scores than their peers who were exposed to fewer risk factors; (b) different promotive and protective factors will emerge as significant contributors depending on the nature of the achievement-related outcome that is being assessed; and (c) protective factors will be identified whose effects are magnified in the presence of multiple risks.

\section{METHOD}

\section{Participants}

The participants for this study were assessed during their seventh-grade year as part of the Maryland Adolescent Development In Context (MADIC) study. MADIC is a study of adolescents, their families, and their schools in a large county in Maryland. MADIC is a part of a larger study funded by the MacArthur Network on Successful Adolescent Development. This larger project was a population study of all students attending 1 of the 23 middle schools in the large countywide school district in which our study was taking place. Eighteen of the schools housed Grades 7 and 8, four included Grade 6, and one included Grades 5 and 6. This larger project is described in a forthcoming book by Cook (1998) and in a paper by Jessor (1993).

In this study, families of seventh-grade students who were participating in the larger study were contacted $(N=1948)$. In the fall of the academic year, a brief description of the study was sent home with each student. Seventy-six percent $(n=1,481)$ participated in the first wave of data collection. The racial distribution of the sample matched the county at large; $61 \%$ were African American families $(n=897), 31 \%$ were European American families $(n=460)$, and $8 \%$ reported mixed racial-ethnic heritage $(n=124)$. There were many different reasons the other $24 \%$ did not participate in the study. Most declined because of time constraints, scheduling conflicts, or lack of interest. Some were never reached because of difficulties obtaining current phone and address information. The schools did not permit us to contact the families who did not return the permission slip, and so we are unable to explain their nonparticipation. 
For this paper, only the data from African American primary caregivers who were mothers $(93 \%)$ and their early adolescent children were used $(n=837)$. Forty-eight percent of these adolescents were females $(n=402)$, and $52 \%$ were males $(n=435)$. Family median income for the 837 families for the past year (1990) was between $\$ 40,000$ and $\$ 44,999$. Although the sample, as a whole, made slightly more than the median income for families with children in the United States, there was a wide range of income distribution. For example, $20 \%$ of the sample made less than $\$ 25,000,40 \%$ made between $\$ 25,000$ and $\$ 50,000,25 \%$ made between $\$ 50,000$ and $\$ 65,000$, and $15 \%$ made above $\$ 65,000$. In addition, $7 \%$ of the sample lived at or below the U.S. poverty threshold. ${ }^{2}$ The average occupation of the head of household was a semiprofessional or skilled worker, but ranged from professionals with advanced degrees to unskilled workers. The average education of the head of household was some post high school education. Fifty-seven percent of the families were married, $12 \%$ were separated, $16 \%$ were divorced, $3 \%$ were widowed, and $12 \%$ were never married. Of those who were not married, $16 \%$ were living with a partner. There was an average of 1.89 children per household. The mean age of the mothers was 39 years and ranged from 28 to 56 years and the mean age of the adolescents was 12 years and ranged from 11 to 16 years.

\section{Procedure}

Residents from the local area were recruited as interviewers and trained in a 3-day workshop. The racial composition of the mostly female interviewers roughly matched that of the county at large (60\% African American, $38 \%$ European American, 2\% Hispanic). Interviewers were paid per interview. To ensure that interviewers were following the interview protocol accurately, approximately $15 \%$ of families were randomly selected and recontacted by the study staff to verify that the interview had taken place and the interviewer had followed the guidelines for conducting the interviews. These verification calls revealed no problems with the interview staff.

In each family, the primary caregiver and the target adolescent were interviewed and given a self-administered questionnaire to complete. The interviewer phoned the household and asked to speak with the parent identified by the school, generally the mother. After describing the study and obtaining his or her agreement to participate, the interviewer asked this adult,

\footnotetext{
${ }^{2}$ The measurement of the U.S. poverty threshold was developed in the 1960 s and is adjusted each year for changes in the cost of living using the Consumer Price Index. In 1990, the weighted average thresholds for families of three, four, five, six, seven, and eight persons were $\$ 10,419$, $\$ 13,359, \$ 15,792, \$ 17,839, \$ 20,241, \$ 22,582$, respectively (U.S. Census Bureau, 1997).
} 
"Out of the people living in this household, what is the name of the person who has the most responsibility for and knows the most about (the target adolescent)?" The person named in response to this question was identified as the primary caregiver. Although the primary caregivers included fathers, grandparents, and other relatives $(7 \%)$, only families in which the adolescent's mother was named as the primary caregiver were used in the following analyses.

Following the initial phone contact, the remainder of the interviewing process took place in the home of the family. The primary caregiver and the target adolescent completed two questionnaires: one a face-to-face structured interview and the other a self-administered questionnaire in a quiet, private place in the home. The primary caregiver was interviewed first and the adolescent second. For both interviews, a card containing all relevant response scales was provided to the respondent. Interviewers asked respondents to refer to this card rather than reading each response scale. Interviewers also were instructed to read all the questions exactly as written in the books and not to define words or interpret questions for the respondents. Each face-to-face interview took $1 \mathrm{hr}$ and each self-administered booklet took $30 \mathrm{~min}$ to complete. The target adolescent and primary caregiver were each given $\$ 15$ for his or her participation.

\section{Measures}

The specific constructs used in this paper are described below. Scale construction was guided by theoretical concerns and factor analyses. Risk factors were selected to be comparable to those used by Sameroff et al. (1993). ${ }^{3}$ Means and standard deviations for the multiple risk score, positive factors, and achievement-related outcomes are presented in Table I. Unless measures contained only a single item or were constructed using a count, reliability estimates for the data presented are in parentheses.

\section{MULTIPLE RISK SCORE}

To calculate a multiple risk score for each family, risk variables were converted to dichotomous factors coded as 1 for present and 0 for absent.

\footnotetext{
${ }^{3}$ Maternal rather than paternal characteristics were chosen as the risk factors for two reasons. First, previous studies examining multiple risk scores have focused on maternal rather than paternal characteristics (Sameroff et al., 1987, 1993). Second, as most of the primary caregivers in this sample were the children's mother, maternal characteristics were more predictive of children's developmental outcomes.
} 


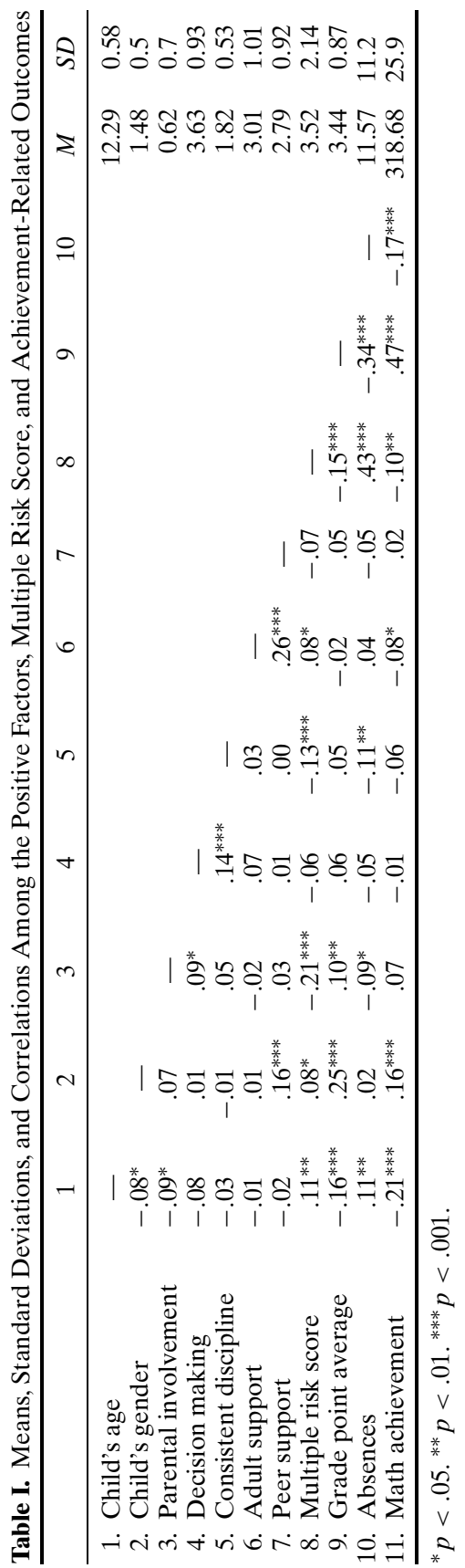


The measure of each risk variable is provided below. In the case of continuous variables where objective categorical definitions of risk were not available, the presence of risk was defined according to the lower quintile $(20 \%)$ of the sample. The calculation of the multiple risk score is discussed further in the Results section.

Maternal Education was a single item in the interview where mothers were asked, "What is the highest grade of school you have completed?" Responses were coded as $1=$ high school degree or less; $2=$ some college; $3=$ college degree; or $4=$ advanced degree. A high school degree or less was in the risk category $(43 \%){ }^{4}$

Maternal Depression $(\alpha=.82)$ was measured in the self-administered questionnaire. Mothers were asked four items adapted from the Symptom Checklist-90-Revised (Derogatis, 1983): "During the past couple of months, how often have you felt hopeless?"; "felt lonely?"; "felt like you don't care anymore?"; and "felt depressed?" Each item was rated on a 5-point scale anchored with $1=$ almost never; $3=$ sometimes; $5=$ almost always. Scores of 3 or higher were in the risk category ( $22 \%$ ).

Marital Status was a single item in the interview where mothers were asked, "What is your current marital status?" Responses were coded as $1=$ not married and $0=$ married/living with a partner. Not married was in the risk category $(27 \%)$.

Number of Children in the Household was a single item in the interview where mothers were asked, "List the number of children under 18 who are presently living in your household on a full-time basis." Families with three or more children were in the risk category $(21 \%)$.

Family Stressful Events was measured in the interview. It consists of a count of the number of stressful events the family had experienced during the past year. Mothers were asked twelve items adapted from the Rochester Longitudinal Study (Baldwin et al., 1993) including "During the past 12 months, did you (or your spouse/partner) become a victim of a violent crime?"; "someone close to you become the victim of a violent crime?"; "change jobs for a worse one?"; "get demoted, have trouble at work, or trouble with the boss?"; "take a cut in wage or salary?"; "get laid off or fired?"; "get in trouble with the law?"; "have a serious injury?"; "did your child have as serious injury or accident?"; "did one of your children get

\footnotetext{
${ }^{4}$ We used a high school degree or less as the risk category for maternal education for two reasons. First, because our sample included families with a wide distribution of exposure to risk, less than $5 \%$ of mothers had less than 12 years of education. Second, it met both criteria indicating that a cutoff of a high school degree or less was indeed a risk factor for African American families living in this particular county. However, it should be noted that previous studies have used less than a high school degree as the risk category (e.g., Sameroff et al., 1993).
} 
seriously ill?"; "did someone close to you get seriously ill or injured?"; "did someone close to you die?"; and "did a close friend or relative have a child die?" Responses were coded as $1=$ yes and $0=n o$. Families who had three or more stressful events were placed in the risk category (15\%).

Family Income was a single item in the interview where mothers were asked, "From all sources of income you mentioned, what was your total family income before taxes in 1990?" Families with an income of $\$ 24,999$ or less were assigned to the risk category $(20 \%)$.

Highest Occupation in the Household was measured in the interview. Mothers were asked their own occupation and, in two-parent homes, the occupation of their spouse/partner. These questions were coded using the U.S. Census Bureau's Occupational Classification System from the 1980 census. No two occupations receive the same code. Inter-rater reliability was established using approximately 200 responses and was $90 \%$ or greater for all coders. An occupation of unskilled worker or less was considered in the risk category $(13 \%)$.

Percent Neighborhood Poverty, Percent Neighborhood Female Headed Households, and Percent Neighborhood Welfare Recipients were measured using 1990 census tract information to reflect adverse community conditions for each family. Families living in neighborhoods with $10 \%$ or more poverty $(20 \%), 41 \%$ or more female-headed households $(20 \%)$, and $8 \%$ or more welfare recipients $(20 \%)$ were assigned to the risk category.

\section{POSITIVE FACTORS}

\section{Family Factors}

Consistent Discipline ( $\alpha=.59$ ) was measured in the interview. Mothers were asked their perceptions of the consistency of their discipline with their adolescent. Five items were taken from the Philadelphia Family Management Study (Furstenberg, Cook, Eccles, Elder, \& Sameroff, 1999) including "If a punishment has been decided upon, how often can youth change it by talking you out of it?"; "If a punishment has been decided upon, how often do you give up trying to get youth to do it?"; "If you warn youth that he/she will be punished if he/she does not stop doing something, how often do you actually punish him/her if he/she does not stop?"; "If youth has been punished, how often does punishment work?"; and "Does the kind of punishment you give youth depend on whether you are in a good or bad mood?" Items were on a 5 -point scale anchored with $1=$ very often; $3=$ occasionally $; 5=$ never.

Democratic Decision-Making $(\alpha=.74)$ was measured in the selfadministered questionnaire. Mothers were asked about their perceptions 
of the degree of control versus autonomy they give to their adolescent in decision-making situations. Four items were modified from the Epstein and McPartland (1977) Family Decision-Making Scale. Items include "How often do you ask your 7 th grader what s/he thinks before deciding on family matters that involve him/her?"; "How often do you ask your child what he/she thinks before making decisions that affect him/her?"; "I encourage my 7th grader to give his/her ideas and opinions even if we might disagree?"; and "I find that listening to what my 7th grader has to say helps me reach a better decision?" Although Epstein and McPartland used a dichotomous format, this scale used a 5-point scale anchored with $1=$ almost never $;=$ about half the time $; 5=$ almost always to increase the variability and better describe the broad range of parent-child authority relationships.

Parental School Involvement was measured in the interview. The scale consisted of a count of the number of school activities the mother was involved in during the past year including school staff, school program supporter, classroom volunteer, advocate, decision maker, and policymaker. The six items were based on surveys designed by Epstein $(1987,1990)$.

\section{Social Support Factors}

Teacher Support $(\alpha=.80)$ was measured in the interview. Adolescents were asked four items taken from The Michigan Study of Adolescent Life Transitions (Eccles \& Barber, 1993) including "When you have a social or personal problem at school, how often can you depend on your teachers to help?"; "When you have a social or personal problem at school, how often can you depend on other adults in the school for help?"; "If you are having trouble on schoolwork, how often can you go to your teachers for help?"; and "If you are having trouble on schoolwork, how often can you go to other adults in the school for help?" Items were on a 5-point scale anchored with $1=$ almost never $; 3=$ about half the time $; 5=$ almost always.

Peer Support $(\alpha=.78)$ was measured in the interview. Adolescents were asked four items taken from The Michigan Study of Adolescent Life Transitions (Eccles \& Barber, 1993) including "When you have a social or personal problem at school, how often can you depend on friends to help you out?"; "When you have a social or personal problem at school, how often can you depend on other students in the school to help you out?"; "If you are having trouble on schoolwork, how often can you go to your friends for help?"; and "If you are having trouble on schoolwork, how often can you go to other students for help?" Items were on a 5-point scale anchored with $1=$ almost never $;=$ about half the time $; 5=$ almost always. 


\section{Achievement Measures}

The three outcomes including grade point averages, number of absences, and Maryland State Math Readiness test scores ${ }^{5}$ were obtained from school records for each seventh grader participating in the study. Students took the Maryland State Math Readiness test at the beginning of the seventh grade. Grade point average included only core academic courses including English, math, science, and social studies.

\section{RESULTS}

For ease of presentation, the results are reported in four sections. The first discusses the calculation of the multiple risk score. The second section examines correlations between the positive factors, multiple risk score, and achievement-related outcomes. The third section examines the effects of the multiple risk score on the achievement-related outcomes. The final section examines the differential effects of the promotive and protective factors on the achievement-related outcomes.

\section{Multiple Risk Score}

The set of risk factors was summarized in a single composite score to simplify statistical analyses. We used two different criteria to determine if each variable was indeed a risk factor (Sameroff, Seifer, \& Bartko, 1997). The first criterion was that the risk variable was correlated with one of the three achievement-related outcomes. All of the risk factors were significantly correlated with at least two of the achievement-related outcomes (see Table II). The significant relationships were in the expected direction and were generally low-to-moderate in magnitude. The second criterion was that there was a significant difference in the achievement-related outcomes between adolescents in the present versus absent risk group, that is, those adolescents who were exposed to a particular risk and those adolescents without the risk. For example, for marital status, we examined whether there was a significant difference in the three achievement-related outcomes between those adolescents who did not have father or stepfather present in the household $(27 \%)$ and those who did.

The results of the $t$ tests between the present and absent risk groups indicated that there was a significant difference between the groups in at

\footnotetext{
${ }^{5}$ A math achievement test was the only standardized achievement test given to students in this district during the seventh grade.
} 
Table II. Identifying Risk Factors

\begin{tabular}{|c|c|c|c|c|c|c|}
\hline \multirow[b]{2}{*}{ Domain } & \multicolumn{2}{|c|}{$\begin{array}{l}\text { Grade point } \\
\text { average }\end{array}$} & \multicolumn{2}{|c|}{$\begin{array}{l}\text { Number of } \\
\text { absences }\end{array}$} & \multicolumn{2}{|c|}{$\begin{array}{l}\text { Math achievement } \\
\text { score }\end{array}$} \\
\hline & $t$ & $r$ & $t$ & $r$ & $t$ & $r$ \\
\hline Maternal education & $5.77^{* *}$ & $23^{* * *}$ & $-6.49^{* * *}$ & $-.25^{* * *}$ & $3.93^{* * *}$ & $.21^{* * *}$ \\
\hline Maternal depression & 1.78 & $-.13^{* * *}$ & $3.49^{* * *}$ & $.18^{* * *}$ & .38 & -.04 \\
\hline Marital status & $4.64^{* *}$ & $-.18^{* * *}$ & $-4.37^{* * *}$ & $.21^{* * *}$ & 1.74 & $-.11^{* *}$ \\
\hline $\begin{array}{l}\text { Number of children in } \\
\text { household }\end{array}$ & 0.64 & $-.08^{*}$ & $-2.82^{* * *}$ & $.17^{* * *}$ & $-2.19^{*}$ & .06 \\
\hline Family stressful events & 0.95 & -.06 & $-3.31^{* * *}$ & $.09^{*}$ & $-2.72^{* *}$ & $.13^{* * * *}$ \\
\hline Highest occupation & $3.05^{* *}$ & $.18^{* * *}$ & $-3.51^{* * *}$ & $-.25^{* * *}$ & 1.75 & $.12^{* * *}$ \\
\hline Family income & $4.95^{* *}$ & $.29^{* * *}$ & $-5.21^{* * *}$ & $.38^{* * *}$ & 1.54 & $.16^{* * *}$ \\
\hline neighborhood poverty (\%) & $2.23^{*}$ & $-.16^{* * *}$ & $-5.06^{* * *}$ & $.30^{* * *}$ & $2.11^{*}$ & $-.11^{* *}$ \\
\hline neighborhood female (\%) & $5.48^{* *}$ & $-.23^{* * *}$ & $-6.60^{* * *}$ & $.27^{* * *}$ & $2.58^{* *}$ & $-.12^{* *}$ \\
\hline $\begin{array}{l}\text { Headed households } \\
\text { neighborhood welfare } \\
\text { recipients }(\%)\end{array}$ & $3.03^{* *}$ & $-.12^{* * *}$ & $-5.37^{* * *}$ & $.24^{* * *}$ & $1.86^{*}$ & $-.14^{* * *}$ \\
\hline
\end{tabular}

least one or more of the three achievement-related measures for each of the 10 risk factors (see Table II). Because all of the variables met these two criteria, the dichotomous risk factors were then summed for each family to produce a composite risk score. The resulting range was from 0 to 10 out of 10 possible risk factors. The mean number of risks was 3.52 with a mode of two risks $(S D=2.14)$. There was a wide distribution of risk scores with 14 families who had no risk factors and 5 families who had all 10 risk factors.

\section{Correlational Analyses}

Table I presents means, standard deviations, and correlations among the positive factors, multiple risk score, and achievement-related outcomes. As expected, adolescents with higher grade point averages were more likely to have fewer absences and higher achievement test scores. For the relations among the risk score and the positive factors, adolescents with lower multiple risk scores were more likely to have mothers who provided consistent discipline and were involved in their school. Unexpectedly, however, adolescents with lower multiple risk scores were also less likely to report teacher support. The multiple risk score, however, was not significantly correlated with democratic decision-making and peer support. For the relations among the positive factors and the achievement-related outcomes, adolescents with higher grade point averages and fewer absences in school were more likely to have mothers that were more involved in their school. Adolescents with fewer absences in school were more likely to have mothers who provided consistent discipline. Unexpectedly, however, adolescents with lower achievement test 
scores were more likely to report more adult support in school. Democratic decision-making and peer support, however, were not significantly correlated with any of the achievement-related outcomes. There were also significant relations among the positive variables. Mothers who reported using more democratic decision-making with their adolescents were also more likely to be involved in their school and provide consistent discipline. Adolescents who reported more adult support in school were also more likely to report more peer support.

\section{Multiple Risk Score}

To test the effects of the multiple risk on the three achievement-related outcomes, we performed regression analyses for each of the three achievement-related outcomes. The results revealed that the multiple risk score was a significant predictor of grade point average, $B=-.25, t(1,793)=$ $-54.60, p \leq .001$, Adj. $R^{2}=.06$; number of absences, $B=.42, t(1,817)=$ 183.31, $p \leq .001$, Adj. $R^{2}=.19$; and math achievement test score, $B=-.09$, $t(1,813)=-5.78, p \leq .05$, Adj. $R^{2}=.01$. Adolescents had lower grade point averages, more absences, and lower math achievement test scores as their exposure to risk factors increased. As shown in Fig. 1, the difference between the adolescents with the lowest and highest number of risks was 1.47 (of out 4.0) points for grade point average, 23 days for number of absences, and 24 points for math achievement test score.

\section{Positive Factors}

To test for promotive and protective effects, we performed hierarchical regression analyses for each of the three achievement outcomes (one for each achievement-related measure). This approach, recommended for designs with multiple variables, reveals the unique contribution of the predictor to the outcome, having taken into account the interrelationships among the predictors (Cohen \& Cohen, 1983). Criteria suggested by Cohen and Cohen (1983) were used in determining the order in which variables were entered into the equation. In these analyses, the more proximal factors were entered in first. In the first step, adolescents' age and gender were entered to control for the effects of gender and grade retention. Family processes and social support factors were entered in the second and third steps, respectively. The multiple risk score and the interaction terms were entered in the fourth and fifth steps, respectively. The two-way interaction terms were created by first centering each of the variables and then computing a multiplicative interaction term (Jaccard, Turissi, \& Wan, 1990). 

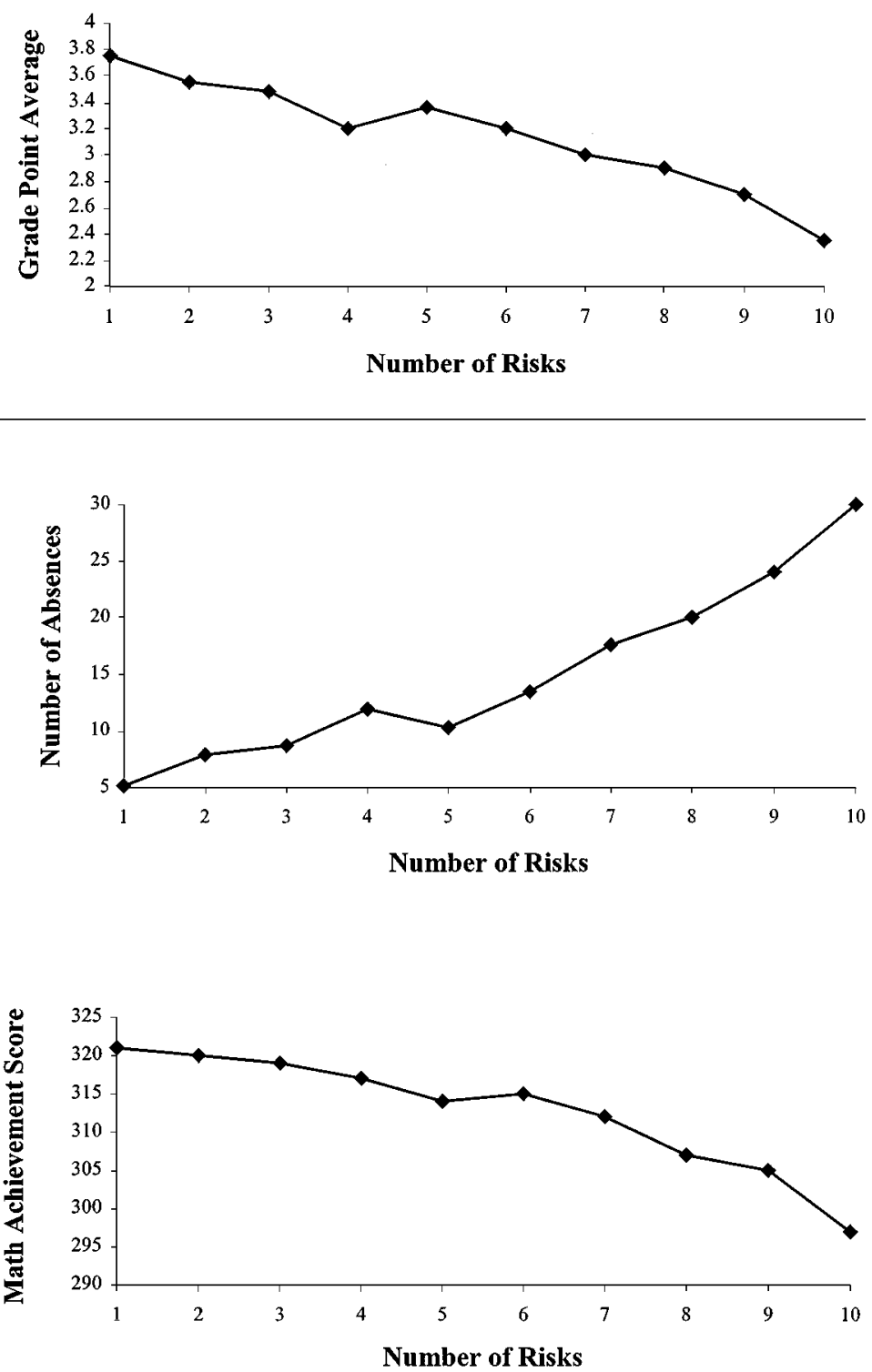

Fig. 1. Effects of Multiple Risk Score on grade point average, number of absences in school, and Math Achievement Test Score. 


\section{Grade Point Average}

Table III presents the hierarchical regression results for grade point average. Overall, the model accounted for $17 \%$ of the variance in grade point average. After adolescent's age and gender were taken into account, the family factors accounted for $3 \%$, social support factors accounted for $0 \%$,

Table III. Family and Social Support Factors as Predictors of Grade Point Average

\begin{tabular}{|c|c|c|c|c|c|}
\hline Variable & $R^{2}$ & $\Delta R^{2}$ & $B$ & $S E B$ & $\beta$ \\
\hline Step 1 & .10 & $.10^{* * *}$ & & & \\
\hline Child's age & & & -0.20 & 0.05 & $-.13^{* * *}$ \\
\hline Child's gender & & & 0.48 & 0.06 & $.28^{* * *}$ \\
\hline Step 2 & .13 & $.03^{* *}$ & & & \\
\hline Child's age & & & -0.19 & 0.05 & $-.13^{* * *}$ \\
\hline Child's gender & & & 0.47 & 0.06 & $.28^{* * *}$ \\
\hline Parental involvement & & & 0.08 & 0.04 & $.08^{*}$ \\
\hline Youth decision making & & & 0.03 & 0.03 & .03 \\
\hline Consistent discipline & & & 0.12 & 0.06 & $.08^{*}$ \\
\hline Step 3 & .13 & .00 & & & \\
\hline Child's age & & & -0.19 & 0.05 & $-.13^{* * *}$ \\
\hline Child's gender & & & 0.48 & 0.06 & $.28^{* * *}$ \\
\hline Parental involvement & & & 0.09 & 0.04 & $.07^{*}$ \\
\hline Democratic decision-making & & & 0.03 & 0.03 & .03 \\
\hline Consistent discipline & & & 0.12 & 0.05 & $.08^{*}$ \\
\hline Adult support in school & & & -0.01 & 0.03 & -.02 \\
\hline Peer support & & & -0.01 & 0.03 & -.01 \\
\hline Step 4 & .15 & $.02^{* *}$ & & & \\
\hline Child's age & & & -0.16 & 0.05 & $-.11^{* * *}$ \\
\hline Child's gender & & & 0.49 & 0.06 & $.29^{* * *}$ \\
\hline Parental involvement & & & 0.06 & 0.04 & .05 \\
\hline Democratic decision-making & & & 0.02 & 0.03 & .02 \\
\hline Consistent discipline & & & 0.11 & 0.05 & $.07^{*}$ \\
\hline Adult support in school & & & -0.01 & 0.03 & -.01 \\
\hline Peer support & & & -0.01 & 0.03 & -.01 \\
\hline Multiple risk score & & & -0.06 & 0.02 & $-.15^{* * *}$ \\
\hline Step 5 & .17 & $.02^{* *}$ & & & \\
\hline Child's age & & & -0.16 & 0.05 & $-.11^{* * *}$ \\
\hline Child's gender & & & 0.49 & 0.06 & $.29^{* * *}$ \\
\hline Parental involvement & & & 0.01 & 0.07 & .08 \\
\hline Democratic decision-making & & & 0.14 & 0.06 & $.15^{*}$ \\
\hline Consistent discipline & & & 0.02 & 0.05 & .02 \\
\hline Adult support in school & & & 0.00 & 0.05 & .01 \\
\hline Peer support & & & -0.01 & 0.07 & -.01 \\
\hline Multiple risk score & & & -0.12 & 0.08 & -.29 \\
\hline Risk $\times$ Involvement & & & -0.01 & 0.02 & -.04 \\
\hline Risk $\times$ Decision Making & & & -0.03 & 0.01 & $-.30^{*}$ \\
\hline Risk $\times$ Consistent Discipline & & & 0.03 & 0.01 & $.14^{*}$ \\
\hline Risk $\times$ Adult Support & & & 0.00 & 0.01 & -.04 \\
\hline Risk $\times$ Peer Support & & & 0.00 & 0.01 & -.01 \\
\hline
\end{tabular}

Note. Gender is contrast-coded (boys $=-1$; girls =1).

${ }^{*} p \leq .05 .{ }^{* *} p \leq .01{ }^{* * *} p \leq .001$. 
multiple risk score accounted for $2 \%$, and the interaction terms accounted for $2 \%$ of the explained variance. As shown in Table III (see Step 2) parental school involvement and consistent discipline were significant promotive factors. Adolescents whose parents were more involved in their school and provided more consistent discipline had higher grade point averages than did their peers.

As shown in Table III (see Step 5), democratic decision-making and consistent discipline were significant protective factors for grade point average. Significant interactions were found between multiple risk score and democratic decision-making and between multiple risk score and consistent discipline. To interpret these significant interactions, regression analyses were performed using criteria suggested by Jaccard et al. (1990). This approach involved calculating the slope of $Y$ (i.e., achievement-related outcome) on $X^{1}$ (i.e., multiple risk score) at high and low values of $X^{2}$ (protective factor), where "low" was defined as one standard deviation below the mean

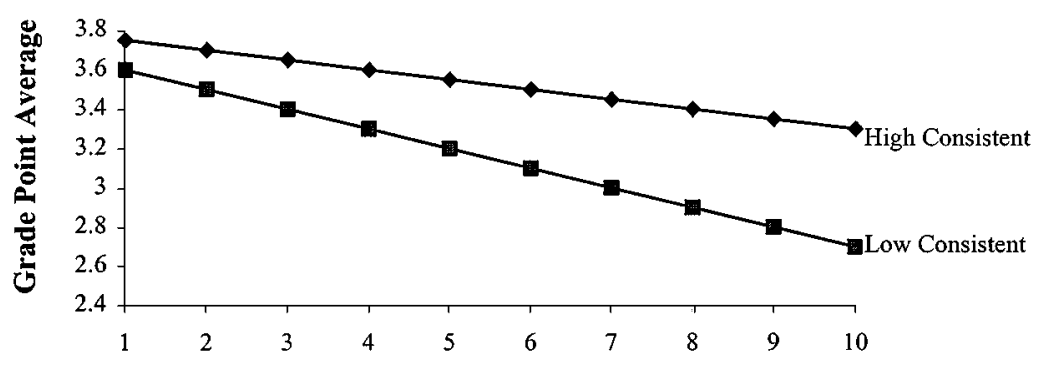

Number of Risk Factors

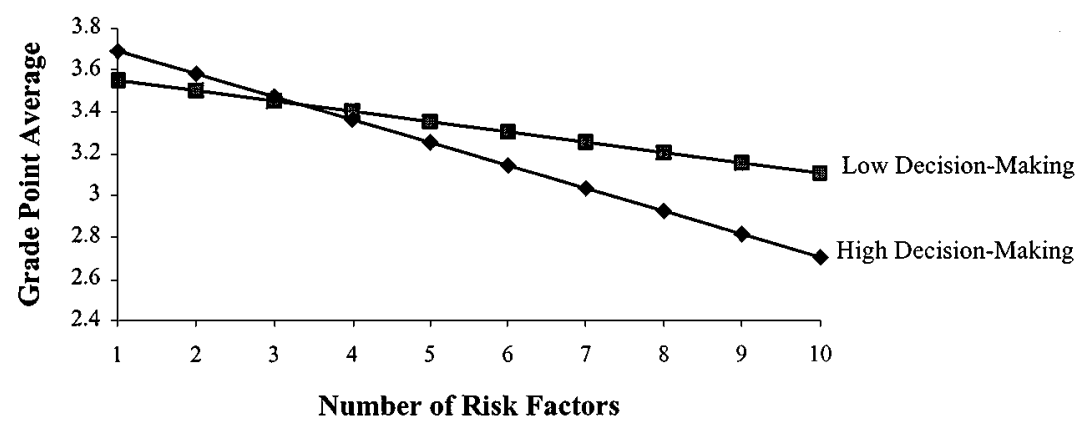

Fig. 2. Interactive effects of Multiple Risk Score and democratic decision-making/ consistent discipline on grade point average. 
and "high" as one standard deviation above the mean. As shown in Fig. 2, adolescents with a greater number of risks had higher grade point averages when they had lower levels of democratic decision-making and higher levels of consistent discipline, whereas adolescents with a fewer number of risks showed little or no differences in their grade point averages regardless of the levels of democratic decision-making or consistent discipline.

\section{Number of Absences}

Table IV presents the hierarchical regression results for number of absences. Overall, the model accounted for $19 \%$ of the variance in number of absences. After adolescent's age and gender were taken into account, the family factors accounted for $3 \%$, social support factors accounted for $0 \%$, multiple risk score accounted for $11 \%$, and the interaction terms accounted for $2 \%$ of the explained variance. As shown in Table IV (see Step 2), parental school involvement and consistent discipline were significant promotive factors. Adolescents whose parents were more involved in their school and provided more consistent discipline had fewer absences than did their peers.

As shown in Table IV (see Step 5), consistent discipline was also a significant protective factor for number of absences. A significant interaction was found between multiple risk score and consistent discipline for number of absences. As shown in Fig. 3, adolescents with a greater number of risks had fewer absences when they had a higher level of consistent discipline, whereas adolescents with a fewer number of risks showed little or no differences in their number of absences regardless of the level of consistent discipline.

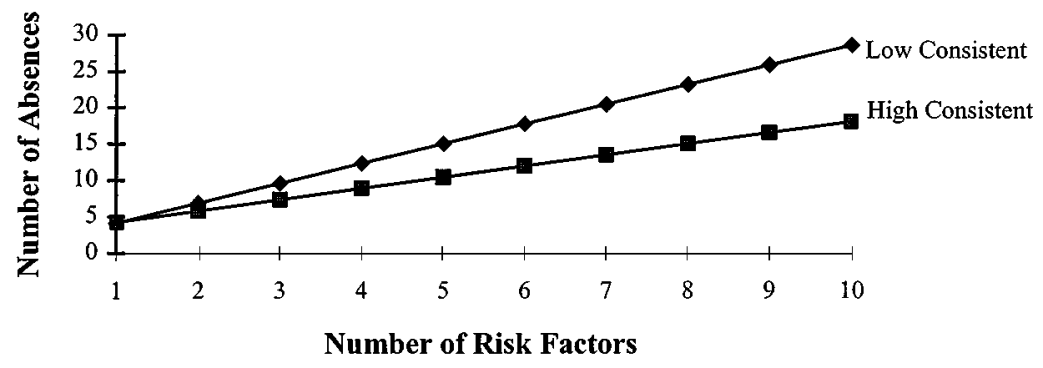

Fig. 3. Interactive effect of Multiple Risk Score and Consistent Discipline on number of absences in school. 
Table IV. Family and Social Support Factors as Predictors of Number of Absences

\begin{tabular}{|c|c|c|c|c|c|}
\hline Variable & $R^{2}$ & $\Delta R^{2}$ & B & $S E B$ & $\beta$ \\
\hline Step 1 & .03 & $.03^{* *}$ & & & \\
\hline Child's age & & & 2.93 & 0.66 & $.15^{\text {*** }}$ \\
\hline Child's gender & & & -1.27 & 0.78 & -.06 \\
\hline Step 2 & .06 & $.03^{* *}$ & & & \\
\hline Child's age & & & 2.80 & 0.65 & $.15^{\text {*** }}$ \\
\hline Child's gender & & & -1.19 & 0.76 & -.05 \\
\hline Parental involvement & & & -1.47 & 0.54 & $-.09^{*}$ \\
\hline Democratic decision-making & & & -0.10 & 0.41 & -.01 \\
\hline Consistent discipline & & & -2.38 & 0.72 & $-.11^{* * *}$ \\
\hline Step 3 & .06 & .00 & & & \\
\hline Child's age & & & 2.81 & 0.58 & $.15^{\text {*** }}$ \\
\hline Child's gender & & & -1.14 & 0.77 & -.05 \\
\hline Parental involvement & & & -1.47 & 0.54 & $-.09 *$ \\
\hline Democratic decision-making & & & -0.09 & 0.42 & -.01 \\
\hline Consistent discipline & & & -2.38 & 0.72 & $-.11^{* * *}$ \\
\hline Adult support in school & & & 0.03 & 0.39 & .00 \\
\hline Peer support & & & -0.18 & 0.44 & -.02 \\
\hline Step 4 & .17 & $.11^{* * *}$ & & & \\
\hline Child's age & & & 2.12 & 0.61 & $.11^{* *}$ \\
\hline Child's gender & & & -1.57 & 0.72 & $-.07^{*}$ \\
\hline Parental involvement & & & -0.47 & 0.51 & -.03 \\
\hline Democratic decision-making & & & 0.04 & 0.39 & .00 \\
\hline Consistent discipline & & & -1.89 & 0.68 & $-.09^{* *}$ \\
\hline Adult support in school & & & -0.32 & 0.37 & -.03 \\
\hline Peer support & & & -0.12 & 0.41 & -.01 \\
\hline Multiple risk score & & & 1.89 & 0.17 & $.36^{* * *}$ \\
\hline Step 5 & .19 & $.02 * *$ & & & \\
\hline Child's age & & & 1.97 & 0.61 & $.10^{* *}$ \\
\hline Child's gender & & & -1.61 & 0.72 & $-.07^{*}$ \\
\hline Parental involvement & & & 0.23 & 0.93 & .02 \\
\hline Democratic decision-making & & & -0.62 & 0.74 & -.05 \\
\hline Consistent discipline & & & -0.42 & 0.87 & -.02 \\
\hline Adult support in school & & & -0.13 & 0.67 & -.01 \\
\hline Peer support & & & -0.94 & 0.82 & -.08 \\
\hline Multiple risk score & & & 0.42 & 0.98 & .08 \\
\hline Risk $\times$ Involvement & & & -0.18 & 0.25 & -.04 \\
\hline Risk $\times$ Decision Making & & & 0.20 & 0.17 & .15 \\
\hline Risk $\times$ Consistent Discipline & & & -0.70 & 0.17 & $-.28^{* * *}$ \\
\hline Risk $\times$ Adult Support & & & -0.05 & 0.18 & -.04 \\
\hline Risk $\times$ Peer Support & & & 0.27 & 0.20 & .17 \\
\hline
\end{tabular}

Note. Gender is contrast-coded (boys $=-1$; girls $=1$ ).

${ }^{*} p \leq .05 .{ }^{* *} p \leq .01{ }^{* * *} p \leq .001$.

\section{Math Achievement Test Score}

Table $\mathrm{V}$ presents the hierarchical regression results for math achievement test score. Overall, the model accounted for $11 \%$ of the variance in math achievement test score. After adolescent's age and gender were taken into account, the family factors accounted for $0 \%$, social support factors 
Table V. Family and Social Support Factors as Predictors of Math Achievement

\begin{tabular}{|c|c|c|c|c|c|}
\hline Variable & $R^{2}$ & $\Delta R^{2}$ & $B$ & $S E B$ & $\beta$ \\
\hline Step 1 & .06 & $.06^{* * *}$ & & & \\
\hline Child's age & & & -9.58 & 1.75 & $-.20^{\text {*** }}$ \\
\hline Child's gender & & & 7.62 & 1.94 & $.15^{* * *}$ \\
\hline Step 2 & .06 & .00 & & & \\
\hline Child's age & & & -9.57 & 1.76 & $-.20^{* * *}$ \\
\hline Child's gender & & & 7.50 & 1.94 & $.14^{* * *}$ \\
\hline Parental involvement & & & 1.33 & 1.37 & .04 \\
\hline Democratic decision-making & & & -0.43 & 1.08 & -.02 \\
\hline Consistent discipline & & & 2.44 & 1.85 & .05 \\
\hline Step 3 & .08 & $.02 *$ & & & \\
\hline Child's age & & & -9.64 & 1.75 & $-.20^{* * *}$ \\
\hline Child's gender & & & 7.45 & 1.96 & $.14^{* * *}$ \\
\hline Parental involvement & & & 1.26 & 1.36 & .04 \\
\hline Democratic decision-making & & & -0.26 & 1.08 & -.01 \\
\hline Consistent discipline & & & 2.33 & 1.85 & .05 \\
\hline Adult support in school & & & -2.21 & 1.00 & $-.09^{*}$ \\
\hline Peer support & & & -0.13 & 1.12 & .01 \\
\hline Step 4 & .09 & $.01^{*}$ & & & \\
\hline Child's age & & & -9.36 & 1.75 & $-.20^{* * *}$ \\
\hline Child's gender & & & 7.87 & 1.96 & $.15^{* * *}$ \\
\hline Parental involvement & & & 0.71 & 1.38 & .02 \\
\hline Democratic decision-making & & & -0.33 & 1.08 & -.01 \\
\hline Consistent discipline & & & 2.54 & 1.85 & .05 \\
\hline Adult support in school & & & -2.03 & 1.00 & $-.08^{*}$ \\
\hline Peer support & & & 0.01 & 1.12 & .00 \\
\hline Multiple risk score & & & -1.00 & 0.48 & $-.08^{*}$ \\
\hline Step 5 & .11 & $.02 * *$ & & & \\
\hline Child's age & & & -9.34 & 1.75 & $-.20^{\text {*** }}$ \\
\hline Child's gender & & & 8.09 & 1.96 & $.16^{* * *}$ \\
\hline Parental involvement & & & 0.41 & 2.50 & .01 \\
\hline Democratic decision-making & & & 4.08 & 2.02 & $.14^{*}$ \\
\hline Consistent discipline & & & 4.32 & 2.44 & .09 \\
\hline Adult support in school & & & -3.29 & 1.80 & -.13 \\
\hline Peer support & & & -3.90 & 2.20 & -.14 \\
\hline Multiple risk score & & & -0.27 & 2.72 & -.02 \\
\hline Risk $\times$ Involvement & & & -0.01 & 0.68 & -.00 \\
\hline Risk $\times$ Decision Making & & & -1.23 & 0.49 & $-.38^{*}$ \\
\hline Risk $\times$ Consistent Discipline & & & -0.42 & 0.48 & -.07 \\
\hline Risk $\times$ Adult Support & & & 0.36 & 0.48 & .11 \\
\hline Risk $\times$ Peer Support & & & 1.12 & 0.56 & $.29^{*}$ \\
\hline
\end{tabular}

Note. Gender is contrast-coded (boys $=-1$; girls $=1$ ).

${ }^{*} p \leq .05 .{ }^{* *} p \leq .01{ }^{* * *} p \leq .001$.

accounted for $2 \%$, multiple risk score accounted for $1 \%$, and the interaction terms accounted for $2 \%$ of the explained variance. As shown in Table V (see Step 3), adult support in school was significant predictor for math achievement test score. Although hypothesized to have a positive effect, adolescents who perceived their teachers as being more supportive had lower math achievement test scores than did their peers. 


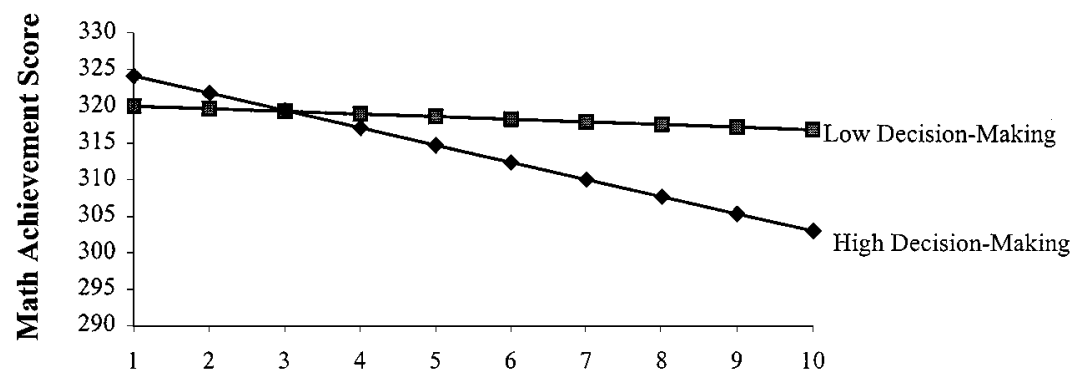

Number of Risk Factors

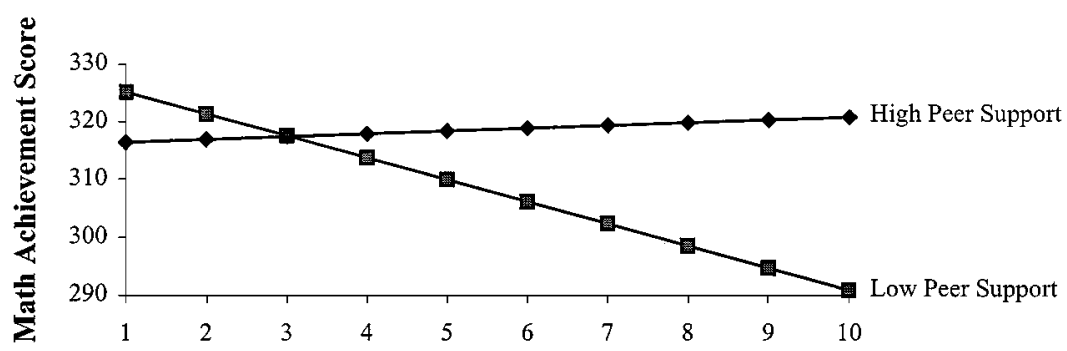

Number of Risk Factors

Fig. 4. Interactive effects of Multiple Risk Score and democratic decision-making/peer support on Math Achievement Test Score.

As shown in Table V (see Step 5), democratic decision-making and peer support were significant protective factors for math achievement test score. Significant interactions were found between multiple risk score and democratic decision-making, and between multiple risk score and peer support. As shown in Fig. 4, adolescents with a greater number of risks had higher math achievement test scores when they had lower levels of democratic decisionmaking and higher levels of peer support, whereas adolescents with a fewer number of risks showed little or no differences in their math achievement test scores regardless of the levels of democratic decision-making or peer support.

\section{DISCUSSION}

In this study, we found three main findings. First, adolescents had lower grade point averages, more absences, and lower math achievement test 
scores as their exposure to risks increased. Second, different promotive and protective factors emerged as significant contributors depending on the nature of the achievement-related outcome that was being assessed. Third, protective factors were identified whose effects were magnified in the presence of multiple risks. Each of these findings is discussed below.

\section{Multiple Risk Score}

Consistent with past research (Rutter, 1979; Sameroff et al., 1987, 1993), we found that the more risk factors adolescents experienced the worse their developmental outcomes. As the number of risk factors increased, adolescents had lower grade point averages, more absences, and lower math achievement test scores. Of interest, we also found that the multiple risk score had a greater association with adolescents' grade point averages and number of absences than their math achievement test scores. This suggests that grade point average and number of absences may be more strongly related to risk than achievement test scores for African American youth during early adolescence. Because the math achievement test scores were based on a single testing session designed to measure a student's math ability, they may be more stable. In contrast, grade point average and number of absences were based on students' performance over the entire school year, and therefore, they may be more pervious to the multiple risks that exist in adolescents' lives. However, this finding needs to be tested further as it relies solely on students' math achievement test scores, as opposed to general achievement test scores.

\section{Promotive Effects of Family Processes and Social Support Factors}

Our study adds to previous studies by examining not only the multiple risks youth experience, but also the differential effects of promotive factors on adolescents' academic outcomes. We found that the promotive effects of family processes and social support factors differed according to the achievement-related outcome that was being assessed. As expected, consistent discipline and parental school involvement had positive effects on adolescents' grade point average and number of absences. This finding is consonant with previous research suggesting that variation in consistent discipline and parental school involvement contributes to disparities within and across income groups (Clark, 1983; Comer, 1980; Eccles \& Harold, 1993; Gutman \& McLoyd, 2000). In contrast, democratic decision-making was not a promotive factor for any of the achievement-related outcomes. 
Rather, it had a protective effect. As discussed in the following section, fewer opportunities for democratic decision-making were associated with higher grade point averages and math achievement test scores only for those adolescents exposed to multiple risks.

Contrary to our expectations, teacher support was negatively related to adolescents' math achievement test score. This finding contradicts other studies that have found either positive (Cauce et al., 1992) or negligible effects of teacher support (Dubow et al., 1991) on children's academic outcomes. This discrepancy may be due to the different types of social support measures that were used across studies. For example, Cauce et al. (1992) measured students' perceptions of the helpfulness of school personnel including teachers and coaches, whereas Dubow et al. (1991) assessed "esteem support" from teachers only (e.g., whether the child feels his teachers are good to ask for help about problems). In contrast, in our study, teacher support focused on adolescents' perceptions of whether they could depend on teachers and other adults in the school for help when they had personal or academic problems. Therefore, since we specifically asked about personal and academic problems, students in our study who elicited more teacher support may also have been those students who were more likely to experience personal and academic difficulties. Unexpectedly, peer support was not a promotive factor. Instead, it had a protective effect. As with democratic decision-making, peer support was associated with higher math achievement test scores only for those adolescents facing multiple risks.

\section{Protective Effects of Family Processes and Social Support Factors}

We also extend previous research by identifying the family processes and social support factors that may protect children exposed to multiple risks from experiencing academic difficulties. There were two major findings for adolescents with a greater number of risks. First, for the family processes, adolescents whose parents provided more consistent discipline had higher grade point averages and fewer absences from school than did their peers whose parents provided inconsistent discipline. On the other hand, adolescents whose parents did not promote democratic decision-making had higher grade point averages and math achievement test scores than did their peers whose parents promoted their decision-making opportunities. Second, for the social support factors, adolescents who reported more peer support had higher math achievement test scores than did their peers who reported less peer support. 


\section{Family Processes}

The results of our analyses suggest that consistent discipline is a significant protective factor for African American youth exposed to multiple risks during early adolescence. Consistent discipline was associated with higher grade point averages and fewer absences for adolescents with a greater number of risks, whereas consistent discipline had little or no effect on the grade point average or number of absences of adolescents with a fewer number of risks. Although previous studies have documented the importance of consistent discipline for the achievement of both high and low risk adolescents (Clark, 1983; Grolnick \& Ryan, 1989; Walker et al., 1991), our study adds to these findings by demonstrating that the significance of consistent discipline may be more pronounced for African American adolescents living in risky environments. For African American families experiencing multiple risks, our findings suggest that parents who provide more consistent discipline may be more supportive and conscientious of their children's school achievement and attendance than are parents who provide inconsistent discipline.

Contrary to our expectations, fewer opportunities for democratic decision-making were associated with higher grade point averages and math achievement test scores for African American adolescents with a greater number of risks, whereas democratic decision-making had little or no effect on the grade point averages and math achievement test scores of adolescents with a fewer number of risks. Although this finding was unexpected, it is not surprising when considering the context of higher risk environment. Parenting practices that are associated with positive developmental outcomes for children and adolescents depend on the values and demands of the larger social context in which the family lives. Considering this, parenting practices that emphasize democratic decision-making and foster a sense of autonomy may be more suitable for children from low risk environments, whereas they may be inappropriate for, or even detrimental to, youth living in more risky environments. Indeed, a number of studies have found that children and adolescents who live in more dangerous environments may benefit from high levels of parental control, whereas children living in less risky neighborhoods may experience negative effects of such restrictive control (Baldwin, Baldwin, \& Cole, 1990; Baumrind, 1972; Furstenberg et al., 1999; Gonzales, Cauce, Friedman, \& Mason, 1996). This may be especially true during early adolescence as youth are just beginning to confront decisions and experience situations that may have profound effects on their life trajectories. And, as our data demonstrate, for African American youth exposed to multiple risks, adolescents with fewer opportunities for democratic decision-making may 
have higher achievement-related outcomes than do their peers with greater opportunities for democratic decision-making.

\section{Social Support Factors}

Although previous research has suggested that peer support is an especially important predictor for the academic success of African American adolescents (Steinberg, Dornbusch, \& Brown, 1992), we found that the significance of peer support is particularly pronounced for African Americans exposed to multiple risks during early adolescence. In particular, we found that peer support was associated with higher math achievement test scores for adolescents with a greater number of risks, whereas peer support did not affect the math achievement test scores of adolescents with a fewer number of risks. Although peer support for academic success may be limited for African American adolescents (Steinberg et al., 1992), our study suggests that African American adolescents exposed to multiple risks who perceive that they can depend on their peers for help with their personal and school difficulties may be more likely to experience higher academic outcomes than are their counterparts who perceive their peers as less supportive.

These findings also uphold previous research suggesting that support from different sources is differentially related to achievement. However, contrary to Cauce et al. (1992), our results indicated that peer support was a protective factor for the math achievement test scores of adolescents experiencing multiple risks, whereas teacher support in school was associated with lower math achievement test scores for the sample as a whole. These results suggest that adult and peer support may provide different avenues of support depending on the needs of the adolescent. For example, a broad spectrum of African American adolescents may experience more academic difficulties when they rely on personal and academic support from their teachers and principals. However, African American adolescents who are facing multiple risks may experience better academic outcomes when they have peers who provide more personal and academic support.

\section{LIMITATIONS AND CONCLUSIONS}

Several limitations must be considered when interpreting the results of this study. First, the reliance on correlational data in this study clearly limits the extent to which conclusions about causality can be made based on the findings. A reasonable argument could be made that outcomes may be associated with, rather than being the result of, these protective factors. 
For example, adolescents exposed to multiple risks who are academically successful may seek more supportive friends. Multimethod designs, such as structural equation modeling or path analytic models, may also strengthen the results of the data given the significant relation between several of the positive factors such as teacher and peer support. The use of data collected at a single time point also limits the conclusions of this study. Considering that the interactive processes between risk and protective factors often rely on chains of connections over time rather than on a multiplicative effect at any single time point (Rutter, 1987), future studies should examine how protective factors change the trajectories of children and adolescents facing multiple risks.

Second, our sample was not completely random and did not include an overrepresentation of families experiencing severe economic problems. Moreover, our families lived in a large, mostly suburban, county of Maryland. As a result, our findings may differ from studies of African American youth living in poor inner-city communities. For example, youth living in areas of concentrated poverty may be more likely to experience a greater number and severity of risk factors. However, our sample does represent an economic cross-section of African American families with a wide distribution of exposure to risk factors. It is also one of the few samples representing a large number of middle-to-upper income African American families. For these reasons, we were able to differentiate between those variables that have a positive influence on a broad spectrum of African American youth from those that only have a special influence on African American youth exposed to multiple risks.

Third, our analyses were not intended to be exhaustive. Other factors such as poor schools have also been shown to produce a context of adversity for youth (Kozol, 1991). Moreover, positive factors such as academic efficacy have been shown to bolster African American students' achievement (Spencer, Cole, DuPree, Glymph, \& Pierre, 1993). Demographic variables, such as gender, may also play a role in academic achievement. For example, our analyses revealed that African American females had higher grade point averages and math achievement test scores than did African American males. These results support previous research indicating that African American males are at a greater risk for academic difficulties than African American females (Carnegie Council of Adolescent Development, 1995; Gutman \& McLoyd, 2000). Future research should examine the specific risks facing African American males and determine whether the effects of promotive and protective factors differ between African American males and females.

Despite this, our study provided substantial support for the hypothesis that African American adolescents experience multiple risks, and the more 
risks they experience, the worse their academic outcomes. Moreover, our study demonstrated that different promotive and protective factors emerge as significant depending on the type of academic outcome being measured. In light of these results, prevention and intervention programs may be more effective if they target multiple risks rather than single risk factors (Coie et al., 1993). However, our results also suggest that it is important to focus on specific protective processes depending on the developmental outcome being targeted in prevention and intervention programs (Masten \& Coatsworth, 1998).

In conclusion, we attempted to clarify the differences between promotive and protective influences on the achievement-related outcomes of African American students during early adolescence. We identified those factors that were promotive only, such as parental school involvement that had positive influences on all youth, and those that were protective only, such as peer support that has positive influences on high risk youth. We also identified consistent discipline as having both promotive and protective effects. Of special interest were those variables that were detrimental to adolescents exposed to multiple risks such as greater opportunities for democratic decision-making. To maximize the efficacy of intervention efforts to foster development, such differentiation is necessary to understand the processes that lead to more or less successful adolescent outcomes. For example, our results suggest that intervention efforts aimed at increasing parental school involvement are important for a broad spectrum of African American students, whereas African American youth exposed to multiple risks may especially benefit from efforts designed to enhance peer networks in early adolescence such as peer mentoring or tutoring programs. Examples of intervention efforts that change school climates with supportive, nurturing environments that emphasize parental involvement and high expectations for all students have been undertaken by researchers including Comer (1980) as well as independent, private and charter schools for African Americans.

\section{REFERENCES}

Baldwin, A. L., Baldwin, C., \& Cole, R. E. (1990). Stress-resistant families and stress-resistant children. In J. E. Rolf (Ed.), Risk and protective factors in the development of psychopathology (pp. 257-280). New York: Cambridge University Press.

Baldwin, A. L., Baldwin, C., Kasser, T., Zax, M., Sameroff, A., \& Seifer, R. (1993). Contextual risk and resiliency during late adolescence. Development and Psychopathology, 5, 741-761.

Baumrind, D. (1972). An exploratory study of socialization effects on black children: Some black-white comparisons. Child Development, 43, 261-267.

Bronfenbrenner, U. (1979). The ecology of human development. Cambridge, MA: Harvard University Press. 
Brooks-Gunn, J., Duncan, G., Klebanov, P. K., \& Sealand, N. (1993). Do neighborhoods influence child and adolescent development? American Journal of Sociology, 99, 353-395.

Carnegie Council on Adolescent Development. (1995). Great transitions: Preparing adolescents for the new century. New York: Author.

Cauce, A. M., Hannan, K., \& Sargeant, M. (1992). Life stress, social support, and locus of control during early adolescence: Interactive effects. American Journal of Community Psychology, 20, 787-798.

Clark, R. (1983). Family life and school achievement: Why poor black children succeed or fail. Chicago: University of Chicago Press.

Cohen, J., \& Cohen, J. (1983). Applied multiple regression/correlation analysis for the behavior sciences (2nd ed.). Hillsdale, NJ: Erlbaum.

Coie, J. D., Watt, N. F., West, S., Hawkins, J. D., Asarnow, J. R., Markman, H. J., et al. (1993). The science of prevention. American Psychologist, 48, 1013-1022.

Comer, J. P. (1980). School power. New York: The Free Press.

Cook, T. (1998). The Prince George's County School study. Manuscript in preparation.

Derogatis, L. R. (1983). SCL-90-R administration, scoring and procedures manual-II (2nd ed.). Townson, MD: Clinical Psychometric Research.

Dubow, E. F., \& Tisak, J. (1989). The relation between stressful life events and adjustment in elementary school children: The role of social support and social problem-solving skills. Child Development, 60, 1412-1423.

Dubow, E. F., Tisak, J., Causey, D., Hryshko, A., \& Reid, G. (1991). A two-year longitudinal study of stressful life events, social support, and social problem-solving skills: Contributions to children's behavioral and academic adjustment. Child Development, 62, 583-599.

Duncan, G. (1994). Families and neighbors as sources of disadvantage in the schooling decisions of White and Black adolescents. American Journal of Education, 103, 20-53.

Eccles, J. S., \& Barber, B. (1993). The Michigan Study of Adolescent Life Transitions. Ann Arbor, MI: Gender and Achievement Research Lab, University of Michigan.

Eccles, J. S., \& Harold, R. D. (1993). Parent-school involvement during the early adolescent years. Teachers College Record, 94, 568-587.

Eccles, J. S., \& Midgley, C. (1989). Stage/environment fit: Developmentally appropriate classrooms for early adolescents. In R. E. Ames \& C. Ames (Eds.), Research on motivation in education (Vol. 3, pp. 139-186). New York: Academic Press.

Eccles, J. S., Midgley, C., Buchanan, C. M., Flanagan, C., Mac Iver, D., Reuman, D., et al. (1993). Development during adolescence: The impact of stage/environment fit. American Psychologist, 48, 90-101.

Epstein, J. L. (1987). What principals should know about parental involvement. Principal, 66, 6-9.

Epstein, J. L. (1990). School and family connections: Theory, research, and implications for integrating sociologies of education and family. Marriage and Family Review, 15, 99-126.

Epstein, J. L., \& McPartland, J. M. (1977). Family and school interactions and main effects on affective outcomes. (Report No. 235). ERIC.

Finn, J. (1989). Withdrawing from school. Review of Educational Research, 59, 117-142.

Ford, D. Y. (1993). Black students' achievement orientation as a function of perceived family achievement orientation and demographic variables. Journal of Negro Education, 62, $47-66$.

Furstenberg, F., Brooks-Gunn, J., \& Morgan, S. P. (1987). Adolescent mothers in later life. Cambridge, England: Cambridge University Press.

Furstenberg, F., Cook, T., Eccles, J., Elder, G., \& Sameroff, A. (1999). Managing to make it: Urban families and adolescent success. Chicago: University of Chicago Press.

Garmezy, N. (1983). Stressors of childhood. In N. Garmezy \& M. Rutter (Eds.), Stress, coping and development in children (pp. 43-84). New York: McGraw-Hill.

Garmezy, N. (1993). Children in poverty: Resilience despite risk. Psychiatry, 56, 127-136.

Gonzales, N. A., Cauce, A. M., Friedman, R. J., \& Mason, C. A. (1996). Family, peer, and neighborhood influences on academic achievement among African American adolescents: One-year prospective effects. American Journal of Community Psychology, 24, 365-388. 
Grolnick, W. S., \& Ryan, R. (1989). Parent styles associated with children's self regulation and competence in school. Journal of Educational Psychology, 81, 143-154.

Gutman, L. M., \& McLoyd, V. C. (2000). Parents' management of their children's education within the home, at school, and in the community: An examination of high-risk African American families. Urban Review, 32, 1-24.

Gutman, L. M., \& Midgley, C. (2000). The role of protective factors in supporting the academic achievement of poor African American students during the middle school transition. Journal of Youth and Adolescence, 29, 223-248.

Hartup, W. W. (1978). Children and their friends. In H. McGurk (Ed.), Issues in childhood social development (pp. 130-170). London: Methuen.

Haveman, R. B., \& Wolfe, B. (1991). Childhood events and circumstances influencing high school completion. Demography, 28, 133-157.

Jaccard, J., Turrisi, R., \& Wan, C. K. (1990). Interaction effects in multiple regression. Newbury Park, CA: Sage Publications.

Jessor, R. (1993). Successful adolescent development among youth in high-risk settings. American Psychologist, 48, 117-126.

Kozol, J. (1991). Savage inequalities: Children in America's schools. New York: Crown Publishers.

Leffert, N., Benson, P. L., Scales, P. C., Sharma, A. R., Drake, D. R., \& Blyth, D. A. (1998). Developmental assets: Measurement and prediction of risk behaviors among adolescents. Applied Developmental Science, 2, 209-230.

Lord, S., Eccles, J. S., \& McCarthy, K. (1994). Surviving the junior high school transition: Family processes and self-perceptions as protective and risk factors. Journal of Early Adolescence, 14, 162-199.

Luthar, S. S., \& Zigler, E. (1991). Vulnerability and competence: A review of research on resilience in childhood. Journal of American Orthopsychiatry, 61, 6-22.

Masten, A. S., \& Coatsworth, J. D. (1998). The development of competence in favorable and unfavorable environments: Lessons from research on successful children. American Psychologist, 53, 205-220.

McLananhan, S., \& Sandefur, G. D. (1994). Growing up with a single parent: What hurts, what helps? Cambridge, MA: Harvard University Press.

McLoyd, V. C. (1990). The impact of economic hardship on black families and children: Psychological distress, parenting, and socioeconomic development. Child Development, 61, 311-346.

McLoyd, V. C. (1998). Socioeconomic disadvantage and child development. American Psychologist, 53, 185-204.

Rolf, J., \& Johnson, J. (1990). Protected or vulnerable: The challenges of AIDS to developmental psychopathology. In J. Rolf, A. S. Masten, D. Cicchetti, K. H. Nuechterlein, \& S. Weintraub (Eds.), Risk and protective factors in the development of psychopathology (pp. 384-404). Cambridge, England: Cambridge University Press.

Rutter, M. (1979). Protective factors in children's responses to stress and disadvantage. In M. W. Kent \& J. E. Rolf (Eds.), Primary prevention of psychopathology: Vol. 3. Social competence in children (pp. 49-74). Hanover, NH: University Press in New England.

Rutter, M. (1987). Psychosocial resilience and protective mechanisms. American Journal of Orthopsychiatry, 57, 316-331.

Sameroff, A. J. (1999). Ecological perspectives on developmental risk. In J. D. Osofsky \& H. E. Fitzgerald (Eds.), WAIMH Handbook of infant mental health: Vol. 4. Infant mental health groups at risk (pp. 223-248). New York: Wiley.

Sameroff, A. J., \& Seifer, R. (1987). Multiple determinants of risk and invulnerability. In E. J. Anthony (Ed.), The invulnerable child (pp. 51-69). New York: Guilford.

Sameroff, A. J., Seifer, R., Baldwin, A., \& Baldwin, C. (1993). Stability of intelligence from preschool to adolescence: The influence of social and family risk factors. Child Development, 64, 80-97.

Sameroff, A. J., Seifer, R., Barocas, R., Zax, M., \& Greenspan, S. (1987). Intelligence quotient scores of 4-year-old children: Social-environmental risk factors. Pediatrics, 79, 343-350. 
Sameroff, A. J., Seifer, R., \& Bartko, T. (1997). Environmental perspectives on adaptation during childhood and adolescence. In S. S. Luthar, J. A. Burack, D. Cicchetti, \& J. R. Weiss (Eds.), Developmental psychopathology (pp. 507-526). Cambridge, England: Cambridge University Press.

Seidman, E., Allen, L., Aber, J. L., Mitchell, C., \& Feinman, J. (1994). The impact of school transitions in early adolescence on the self-system and perceived social context of poor urban youth. Child Development, 65, 507-522.

Shaw, D., \& Emery, R. (1988). Chronic family adversity and school-age children's adjustment. Journal of the American Academy of Child and Adolescent Psychiatry, 27, 200-206.

Slaughter, D. T., \& Epps, E. G. (1987). The home environment and the academic achievement of Black American children and youth: An overview. Journal of Negro Education, 56, 3-20.

Spencer, M. B., Cole, S. P., DuPree, D., Glymph, A., \& Pierre, P. (1993). Self-efficacy among urban African American early adolescents: Exploring issues of risk, vulnerability, and resilience. Development and Psychopathology, 5, 719-739.

Steele, C. M. (1992). Race and the schooling of Black Americans. The Atlantic Monthly, 269, 68-78.

Steinberg, L., Dornbusch, S. M., \& Brown, B. B. (1992). Ethnic differences in adolescent achievement: An ecological perspective. American Psychologist, 47, 723-729.

Stouthhamer-Loeber, M., Loeber, R., Farrington, D. P., Zhang, Q., Van Kammen, W. B., \& Maguin, E. (1993). The double edge of protective and risk factors for delinquency: Interrelations and developmental patterns. Development and Psychopathology, 5, 683701.

Tienda, M., \& Kao, G. (1994). Parental behavior and the odds of success among students at risk of failure. Paper presented at the annual meeting of the American Sociological Association, Los Angeles, CA.

Walker, H. M., Stieber, S., Ramsey, E., \& O’Neill, R. E. (1991). Longitudinal prediction of school achievement, adjustment, and delinquency of antisocial versus at-risk boys. Remedial and Special Education, 12, 43-51.

Werner, E. (1985). Stress and protective factors in children's lives. In A. R. Nicol (Ed.), Longitudinal studies in child psychology and psychiatry (pp. 335-355). New York: Wiley.

U. S. Bureau of Census. (1997). Weighted average poverty thresholds: 1980 to 1995. (Current Population Reports, Series P-60, No. 194) Washington, DC: U.S. Government Printing Office. 